ORIGINAL ARTICLE

\title{
Regulated ATF5 loss-of-function in adult mice blocks formation and causes regression/eradication of gliomas
}

\author{
A Arias ${ }^{1}$, MW Lamé ${ }^{1}$, L Santarelli ${ }^{2,4}, \mathrm{R} \mathrm{Hen}^{2}$, LA Greene ${ }^{3}$ and JM Angelastro ${ }^{1}$ \\ ${ }^{1}$ Department of Molecular Biosciences, University of California, Davis School of Veterinary Medicine, Davis, CA, USA; ${ }^{2}$ Department \\ of Neuroscience, Columbia University, New York, NY, USA and ${ }^{3}$ Department of Pathology and Cell Biology, Columbia University, \\ New York, NY, USA
}

\begin{abstract}
Glioblastomas are among the most incurable cancers. Our past findings indicated that glioblastoma cells, but not neurons or glia, require the transcription factor ATF5 (activating transcription factor 5) for survival. However, it was unknown whether interference with ATF5 function can prevent or promote regression/eradication of malignant gliomas in vivo. To address this issue, we created a mouse model by crossing a human glial fibrillary acidic protein (GFAP) promoter-tetracycline transactivator mouse line with tetracycline operon-dominant negativeATF5 (d/n-ATF5) mice to establish bi-transgenic mice. In this model, d/n-ATF5 expression is controlled by doxycycline and the promoter for GFAP, a marker for stem/ progenitor cells as well as gliomas. Endogenous gliomas were produced with high efficiency by retroviral delivery of platelet-derived growth factor (PDGF)-B and p53-short hairpin RNA (shRNA) in adult bi-transgenic mice in which expression of $\mathrm{d} / \mathrm{n}$-ATF5 was spatially and temporally regulated. Induction of $\mathbf{d} / \mathbf{n}$-ATF5 before delivery of PDGF-B/p53-shRNA virus greatly reduced the proportion of mice that formed tumors. Moreover, d/n-ATF5 induction after tumor formation led to regression/ eradication of detectable gliomas without evident damage to normal brain cells in all 24 mice assessed.
\end{abstract}

Oncogene (2012) 31, 739-751; doi:10.1038/onc.2011.276; published online 4 July 2011

Keywords: ATF5; PDGF-B; tumorigenesis; glioma

\section{Introduction}

Glioblastomas are a particularly devastating form of primary brain tumors; even after surgical resection with subsequent radiation and chemotherapy, the survival time is generally only 12-18 months (Stupp et al., 2005). The highly infiltrative nature of such tumors into normal brain tissue and their heterogeneity make them

Correspondence: Dr JM Angelastro, Department of Molecular Biosciences, University of California, Davis School of Veterinary Medicine, 2165 Haring Hall, One Shields Avenue, Davis, CA 95616 , USA.

E-mail: jmangelastro@ucdavis.edu

${ }^{4}$ Current Address: Hoffmann-La Roche, Basel, Schweiz, Switzerland. Received 13 February 2011; revised 29 April 2011; accepted 26 May 2011; published online 4 July 2011 especially difficult to treat. It is thought that glioblastomas arise by transformation of neural progenitor/stem cells present in the neonatal and adult brain and evidence has been presented that the tumors contain a subpopulation of treatment-resistant cancer stem cells (Vescovi et al., 2006).

This study concerns the potential of activating transcription factor 5 (ATF5), a member of the ATF/ CREB family (see Greene et al. (2009) for a review), as a direct target for the treatment of glioblastomas. In the normal developing brain, ATF5 is highly expressed in neural progenitor/neural stem cells where it promotes cell proliferation and inhibits neurogenesis and gliogenesis (Angelastro et al., 2003, 2005; Mason et al., 2005). ATF5 downregulation is required to permit neural progenitors to differentiate into neurons, astrocytes and oligodendroglia. Conversely, constitutive ATF5 gain-of-function stimulates continued proliferation of neural progenitor cells without differentiation. The latter observation led us to examine ATF5 expression in neural tumors and to the finding that it is highly expressed in human and rat glioblastoma cell lines and in resected human glioblastomas (Angelastro et al., 2006; Monaco et al., 2007). Several studies also indicate that ATF5 appears to be a prognostic marker for malignant gliomas (Dong et al., 2005; Angelastro et al., 2006; Monaco et al., 2007; Sheng et al., 2010). In addition, ATF5 is co-expressed with CD133 (Angelastro et al., 2003; Schrot et al., 2007), a marker for neural stem cells and for at least some populations of glioblastoma stem cells (Singh et al., 2003), and is expressed in stem cells derived from human glioblastoma cell lines (Sheng et al., 2010).

As a preliminary approach to assessing the cellular role of ATF5, we designed a dominant-negative form of ATF5 (d/n-ATF5) as well as an ATF5 small interfering RNA (Angelastro et al., 2003, 2005, 2006; Mason et al., 2005). These caused massive apoptotic death of all eight rat and human glioblastoma cell lines that were assessed (Angelastro et al., 2006). In contrast, ATF5 loss-offunction did not affect survival of cultured neurons or glial cells, but rather promoted the differentiation of neural progenitor cells into neurons and glia and caused cell cycle exit of proliferating cultured astrocytes. In an in vivo study, we further observed that retroviral delivery of $\mathrm{d} / \mathrm{n}$-ATF5 to tumors generated by injection of $\mathrm{C} 6$ glioma cells into rat brain resulted in the death of essentially all tumor cells infected by the virus. In 
contrast, non-neoplastic astrocytes outside the tumors infected with $\mathrm{d} / \mathrm{n}$-ATF5 virus were unharmed (Angelastro et al., 2006). The differential effect of $\mathrm{d} / \mathrm{n}-\mathrm{ATF} 5$ on survival of normal and malignant cells was also seen in a study in which it promoted death of neoplastic, but not of non-transformed human breast cell lines (Monaco et al., 2007).

The aim of this study was to explore whether direct manipulation of ATF5 function would affect the formation as well as maintenance of gliomas generated from endogenous neural stem/progenitor cells in adults and do so without harm to other brain tissues. To this end, we created bi-transgenic mice in which $\mathrm{d} / \mathrm{n}$-ATF5 expression is subject to both spatial and temporal regulation by the human glial fibrillary acidic protein (hGFAP) promoter and the Tet-off system, respectively. The hGFAP promoter directs $\mathrm{d} / \mathrm{n}-\mathrm{ATF} 5$ expression to neural stem/progenitor cells and astrocytes (sites where ATF5 is normally expressed) as well as to gliomas, whereas the Tet-off system (controlled by the presence/ absence of doxycycline in the diet) permits the choice of whether or not, as well as when, d/n-ATF5 is expressed. Generation of gliomas in these mice was achieved by retroviral delivery of platelet-derived growth factor (PDGF)-B. In adult rodents, this approach is highly efficient in producing brain tumors that resemble human glioblastomas (Assanah et al., 2006) and there is evidence that PDGF may be involved in the pathogenesis of glioblastomas and other tumor types (Wang et al., 2010). We report that regulated expression of $\mathrm{d} / \mathrm{n}$-ATF5 suppresses the formation of new gliomas and causes the eradication/regression of pre-existing gliomas in mouse brain.

\section{Results}

ATF5 is expressed in the postnatal mouse brain

Although our earlier work with rats showed that ATF5 is expressed in embryonic neural progenitors and in 10day postnatal rat brain (Angelastro et al., 2003, 2005; Mason et al., 2005), it was important for our studies to establish that ATF5 is expressed in postnatal mouse brain and in cell types that have the potential to give rise to malignant gliomas. As shown by immunohistochemistry, ATF5 protein is expressed by cells within the ependymal zone, subventricular zone (SVZ) and corpus callosum of the 28-day postnatal mouse cerebral cortex (Figures $1 \mathrm{a}-\mathrm{c}$ ), as well as in the hippocampal dentate gyrus subgranular zone (Figure 1f). Comparable expression was seen in brains of 24-week-old mice (data not shown). These areas contain niches for neural stem/ progenitor cells that give rise to neurons and glia in the adult brain (Alvarez-Buylla and Lim, 2004; Riquelme et al., 2008; Mu et al., 2010). Consistent with these results, these $\mathrm{ATF}^{+}$regions were also positive for the neural stem/progenitor cell markers nestin (Figure 1d) and Musashi-1 (Figure 1e). Significantly, ATF5 was coexpressed in a subset of cells that express GFAP (Figures 1b, c and f). Gliomas are thought to arise from $\mathrm{GFAP}^{+}$stem/progenitor cells and also express
GFAP (Jackson and Alvarez-Buylla, 2008). In contrast to the neurogenic zones, other areas of the brain showed little or no immunostaining for ATF5 (Supplementary Figure S1).

Generation of mice with regulated spatial and temporal expression of a $d / n$-ATF5 transgene

To study ATF5 function, we have created a specific interfering $\mathrm{d} / \mathrm{n}$ form of the protein that lacks the $\mathrm{N}$ terminal acidic activation and DNA-binding domains and that contains an enhanced bZip domain (Vinson et al., 1993; Krylov et al., 1995; Moitra et al., 1998; Moll et al., 2000; Angelastro et al., 2006). Flag-tagged d/nATF5 blocks ATF5 function and consequently accelerates differentiation of neural progenitors and induces apoptosis of glioblastoma and other neoplastic cells both in vitro and in vivo (Angelastro et al., 2003, 2005, 2006; Mason et al., 2005; Monaco et al., 2007). For the current studies, we generated a transgenic mouse line in which Flag-tagged-d/n-ATF5 and $\beta$-galactosidase ( $\beta$-gal) (product of LacZ) are driven as separate gene products under the control of the pBi3-tetracycline operon (TETO) operator (Baron et al., 1995). This line was crossed with an hGFAP-tetracycline transactivator (tTA) transgenic mouse line (Pascual et al., 2005; Sweger et al., 2007) in which the hGFAP promoter drives the tTA protein (Gossen and Bujard, 1992; Gossen et al., 1994). This line has been successfully employed to spatially and temporally regulate transgenes such as $d / n$ SNARE, GPCR Ro1 RASSL, Gq-coupled receptor and ErbB2 in neural progenitors and astrocytes (Pascual et al., 2005; Fiacco et al., 2007; Ghashghaei et al., 2007; Sweger et al., 2007). In this 'Tet-off' system, in the absence of doxycycline, the bi-transgenic mice should express $d / n$-ATF5 and $\beta$-gal in cells such as neuroprogenitors and gliomas in which the hGFAP promoter is active; conversely in the presence of dietary doxycycline, d/n-ATF5 expression should be suppressed (Figure 2a).

Examination of the brains of adult bi-transgenic mice exposed to doxycycline since conception revealed no detectable expression of either Flag-d/n-ATF5 or of $\beta$-gal (Figure 2b and Supplementary Figure S2a). In contrast, brains of bi-transgenic animals raised from conception without doxycycline or raised from conception with the drug for 5-29 weeks and then withdrawn from it for 3-7 weeks showed robust expression of Flag$\mathrm{d} / \mathrm{n}$-ATF5 and $\beta$-gal in the cortex and subventricular zone (Figures 2b-e and Supplementary Figure S2b), and the hippocampus (Figure 2c). The co-expression of $\beta$-gal with Flag-d/n-ATF5 (Figure 2c) permitted us to use the former to detect cells where the $\mathrm{d} / \mathrm{n}$-ATF5 was induced. Expression of $\mathrm{d} / \mathrm{n}$-ATF $5 / \beta$-gal persisted in doxycycline withdrawn bi-transgenics for at least 11 months after birth (data not shown). Moreover, bi-transgenic mice raised with doxycycline for 24-29 weeks following conception and then withdrawn from the drug for 6-7 weeks showed co-expression of $\beta$-gal with endogenous GFAP within the cortex (Figure 2d) and SVZ (Figure 2e). In contrast, there was no or very weak $\beta$-gal staining in non-neurogenic regions (Supplementary Figure S1b). 

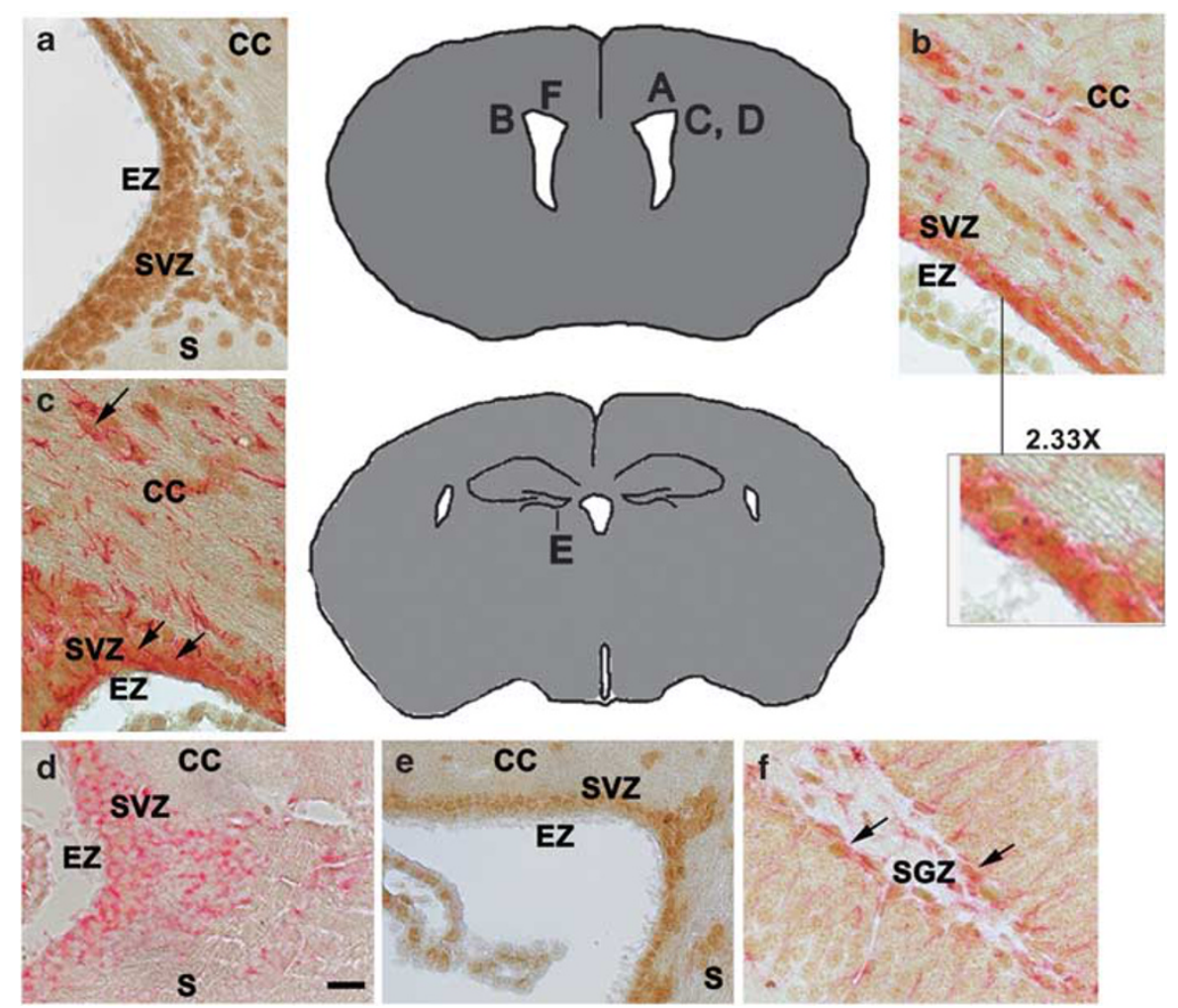

Figure 1 Cells within the neurogenic zones of postnatal mouse brain express ATF5. A paraffin-embedded 28-day postnatal mouse brain was sectioned and immunostained for the following markers: (a) ATF5 (brown). (b) ATF5 (brown) and GFAP (red). The $\times 2.33$ magnification inset shows a subset of cells co-stained for GFAP and ATF5. (c) ATF5 (brown) and GFAP (red). Arrows show a subset of cells along the ventricle and corpus callosum (CC) that co-stain for ATF5 and GFAP. (d) Nestin. (e) Musashi-1. In (a)-(e), note staining within the ependymal zone (EZ), SVZ, CC and the junction between the corpus callosum and the striatum (S). (f) ATF5 (brown) and GFAP (red) in the subgranular zone (SGZ) of the hippocampal dentate gyrus. Arrows show cells co-stained for ATF5 and GFAP. Scale bar $=20 \mu \mathrm{m}$. Diagrams show locations in the brain of corresponding panel letter (adapted from http:// www.hms.harvard.edu/research/brain/atlas).

The long-term persistence of non-transformed brain cells in which $\mathrm{d} / \mathrm{n}$-ATF5 is induced indicates that transgene expression does not cause their death. To further determine whether induced d/n-ATF5 expression affected survival of non-transformed brain cells, we immunostained for cleaved caspase- 3 in brain sections from an animal in which doxycycline had been withdrawn for 45 days. No signal was observed in $d / n-$ ATF5/ $\beta$-gal-expressing cells within the ependymal zone, SVZ, corpus callosum or subgranular zone (Supplementary Figure S3). In addition, there were no evident ill effects or abnormal behavior caused by inducing $\mathrm{d} / \mathrm{n}$ ATF5 expression in the bi-transgenics and the brains of animals raised without, or withdrawn from doxycycline for extended periods all appeared grossly normal other than apparent mild enlargement of the lateral ventricles (perhaps due to reduction in the SVZ progenitor population). Thus, the d/n-ATF5 could be safely induced in adult animals and in $\mathrm{GFAP}^{+}$cells that have the potential to generate malignant gliomas.

Induction of $\mathrm{ATF5}^{+}$malignant glioma cells by ectopic expression of PDGF-B and p53-shRNA

We next sought an adult mouse model for inducible gliomas that resemble human glioblastomas. We elected to employ an approach in which PDGF-B is delivered to proliferating neuroprogenitor/neural stem cells by retroviral infection (Uhrbom et al., 1998, 2000; Dai et al., 2001; Shih et al., 2004; Assanah et al., 2006, 2009). Such cells possess PDGF-A receptors (Jackson et al., 2006; Ogden et al., 2008) and constitutive induction of PDGF signaling leads them to uncontrolled cell replication and to the formation of invasive malignant gliomas (Uhrbom et al., 1998, 2000; Dai and Holland, 2001; Dai et al., 2001; Shih et al., 2004; Assanah et al., 2006, 2009). The advantages of this model are that: (1) a very high percentage of the treated animals develop tumors; (2) PDGF-B-induced tumors exhibit features of human glioblastomas grades IV (2007 World Health Organization classification of human nervous system tumors), including dense cellularity, mitotic figures, nuclear atypia, microvascular proliferation and necrotic foci with surrounding pseudopalisading cells (Dai et al., 2001; Shih et al., 2004; Hede et al., 2009); (3) unlike other glioma models, the PDGF-B paradigm induces tumors in the adult rodent brain (Assanah et al., 2006). To accelerate tumor production (Hesselager et al., 2003), we co-delivered a short-hairpin RNA interference against the tumor suppressor p53 (p53-shRNA). Our past work established that d/n-ATF5 kills cultured 
a

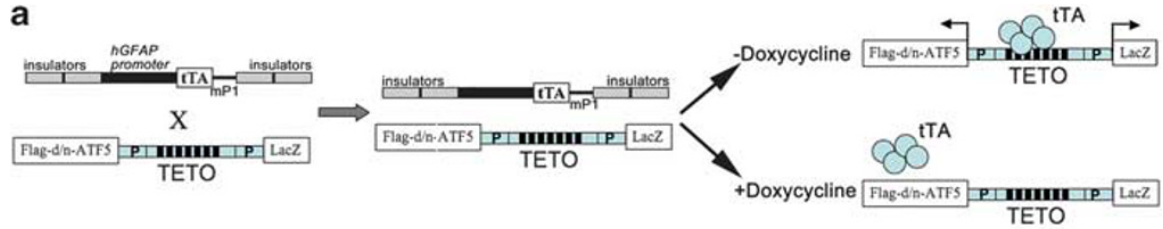

b +Dox FLAG-d/n-ATF5 -Dox
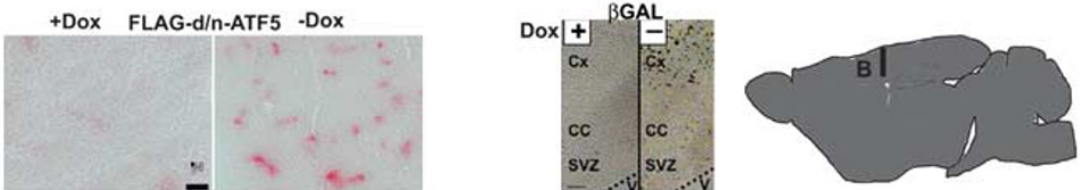

C
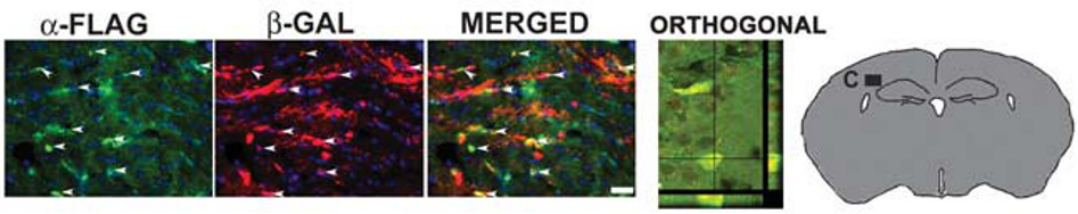

d

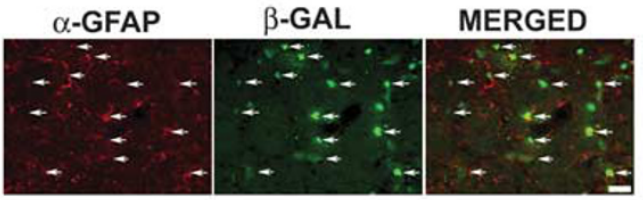

e
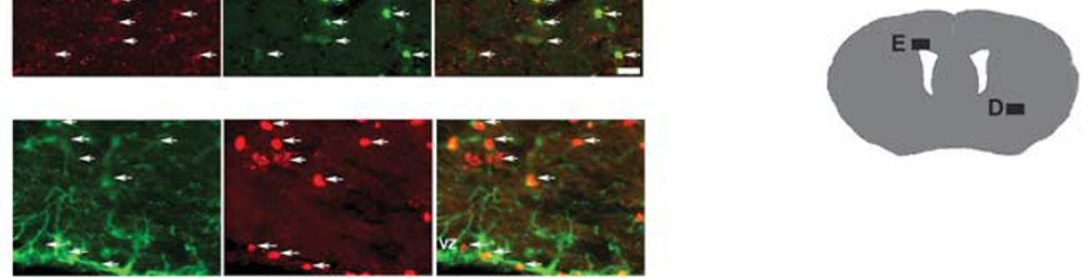

Figure 2 Regulated expression of $d / n$-ATF5 in bi-transgenic hGFAP-tTA $\times$ pBi-TETO-3-Flag-d/n-ATF5/ $\beta$-gal mice. $($ a) Scheme for generation and utilization of bi-transgenic hGFAP-tTA $\times$ pBi-TETO-3-Flag-d/n-ATF5/ $\beta$-gal mice. The hGFAP promoter drives the tTA, and the tTA binds to TETO in the absence of doxycycline (Dox) to induce bi-directional co-expression of the Flag-d/n-ATF5 and $\beta$-gal (LacZ) transgenes. (b) Regulated expression of Flag-d/n-ATF5 (left-hand panels) and $\beta$-gal (right-hand panels) in the cortex, SVZ and CC of bi-transgenic mice. One bi-transgenic mouse was maintained on Dox at conception and killed 63 days after birth ( + Dox), whereas the other was maintained on Dox from conception until 35 days after birth, and then withdrawn from the drug and killed 28 days later (-Dox). Colorimetric staining of Flag-tagged d/n-ATF5 in the cortex (sagittal section) was achieved with antiFLAG M2 antibody and Vulcan Fast Red. Scale bar $=10 \mu \mathrm{m}$. X-gal substrate was used for $\beta$-gal colorimetric detection. V $=$ lateral ventricle; $\mathrm{CC}=$ corpus callosum; $\mathrm{Cx}=$ cortex; $\mathrm{SVZ}=$ subventricular zone. Scale bar $=20 \mu \mathrm{m}$. (c) Coordinately regulated expression of Flag-d/n-ATF5 and $\beta$-gal within the SVZ and near the CA1 region of the hippocampus (orthogonal view) in a 79-day-old bi-transgenic mouse raised without Dox since conception. Immunofluorescence staining was carried out with anti-Flag (for detection of Flag-d/nATF5; green) and $\beta$-gal (red). Arrows in the merged panel indicate cell colocalization. The confocal ( $2 \mu \mathrm{m})$ orthogonal section image shows the $x-y$ and $y-z$ location of both $\beta$-gal and Flag-d/n-ATF5 within the same cell. (d) Regulated expression of $\beta$-gal in GFAP + cells within the cortex of a bi-transgenic mouse. The animal was maintained on Dox from conception until 204 days after birth and the drug was then withdrawn until being killed 50 days later. Panels show immunostaining with anti-GFAP (red) and anti- $\beta$-gal (green) and arrows show the locations of cells in which both are co-expressed. (e) Regulated expression of $\beta$-gal in GFAP ${ }^{+}$cells within the SVZ of a bi-transgenic mouse. The mouse was maintained on doxycycline from conception until 167 days after birth and the drug was then withdrawn until being killed 42 days later. Panels show immunostaining with anti-GFAP (green) and anti- $\beta$-gal (red) and arrows show the locations of cells in which both are co-expressed. Diagrams show the brain areas where photographs were taken (adapted from BrainMaps.org and http://www.hms.harvard.edu/research/brain/atlas). Scale bar $=20 \mu \mathrm{m}(\mathbf{c}-\mathbf{e})$.

glioblastoma cells irrespective of their expression of $\mathrm{p} 53$ (Angelastro et al., 2006).

For our study, we constructed one control retrovirus that encoded short-hairpin-p53 RNA interference (p53shRNA) and the DsRed fluorescent reporter, as well as a tumorigenic retrovirus also encoding PDGF-B-HA (hemagglutinin tagged), besides p53-shRNA and DsRed. The human U6 pol III drives the expression of p53-shRNA, whereas the cytomegalovirus promoter drives DsRed for the control retrovirus and PDGF-BHA and DsRed for the tumorigenic retrovirus (Figure 3a). The retroviruses were stereotactically injected into the SVZ and corpus callosum of the left cerebral hemispheres of the mice at about 10 weeks of age. Injection of the left hemisphere permitted comparison with the unaffected right hemisphere. Brains were harvested at 40-180 days after viral injection, fixed, serially sectioned and stained and examined for the presence of tumors. In some cases, brains were paraffin embedded before sectioning to enhance the detection of tumor tissue.

A large proportion (32/34; see Figure 5 for detailed breakdown) of wild-type (fed with doxycycline), monotransgenic (hGFAP-tTA and pBi3-TETO-Flag-d/nATF5/LacZ; also with or without doxycycline) and bi-transgenic mice (continuously fed with doxycycline) 
developed malignant gliomas in response to injection with the PDGF-B-HA/p53-shRNA retrovirus. Approximately $50 \%$ of animals formed gliomas by 40-45 days post-injection and $94 \%$ between 90 and 180 days post-injection. In contrast, animals receiving retrovirus encoding only p53-shRNA did not form gliomas $(n=3)$ and those injected with virus encoding PDGF-B, but not p53-shRNA, failed to reliably form tumors within 90 days.

The glioma cells were typically diffuse with hyperchromatic irregular nuclei and a sharp reduction in neuronal density (hematoxylin and eosin (H\&E); Figures $3 b, c^{\prime}$ and $\mathrm{e}^{\prime}$ ); about $10 \%$ exhibited pseudopalisading cells around necrotic foci. The tumors were also highly invasive as evidenced by one example in which tumor cells migrated away from the injection site in the septo-diencephalic region to the caudal mesencephalon region (Figure 3e; see also Figures $3 \mathrm{c}$ and $4 \mathrm{a}$, c and Supplementary Figure S4 for additional examples). The appearance of tumor cells far from the site of viral injection was not due to diffusion of the virus. Injection of control p53-shRNA/DsRed retroviruses generated infected cells only at the injection site and these were not invasive (Supplementary Figure S5; see also Assanah et al. (2006)). The high proliferative activity $(100 \%$ index) of the gliomas was indicated by the presence of marked Ki67 staining, which contrasted with the paucity of such staining in the contralateral hemisphere $(0 \%$ index) (Figures $3 \mathrm{j}$ and $\mathrm{k}$ ). As evidence that the tumor cells were derived from cells that took up the virus, they expressed the HA tag (Figures 3c, e and g) and were negative for p53 immunostaining (Figure 3h). This contrasted with normal cells on the contralateral side or that were remote from the tumor cells, which were $\mathrm{HA}^{-}$ and $\mathrm{p} 53^{+}$(Figures 3d, f and i; distal to the tumor). These results were corroborated by staining for DsRed (data not shown). In contrast to normal contralateral brain tissue that has only a small proportion of cells immunoreactive for PDGF-A receptors (Supplementary Figure S4A), the gliomas were strongly positive for PDGF-A receptor expression (Supplementary Figure S4B, C). The glioma cells were also positive for the expression of GFAP (Figure 4c) and, significantly, for ATF5 (Figures $4 \mathrm{a}$ and b). Immunofluorescent microscopy for $\beta$-gal expression in the tumors (as well as in ipsilateral normal brain tissue) in the doxycyclinetreated bi-transgenics showed no immunoreactivity, confirming that the $\mathrm{d} / \mathrm{n}-\mathrm{ATF} 5 / \mathrm{LacZ}$ transgene was not activated in presence of the drug (Figures $4 a$ and b). Finally, another indication of tumor formation in response to the $\mathrm{p} 53$-shRNA/PDGF-B-HA/DsRed retrovirus was moribund behavior. Within the 180-day course of the study, six of the 16 virally injected bitransgenic animals treated with doxycycline since conception to suppress $\mathrm{d} / \mathrm{n}$-ATF5 were judged by veterinary staff to have become moribund and were immediately killed (Figure 5b). All of these were found to harbor gliomas. Taken together, these data provide evidence that the $\mathrm{p} 53-\mathrm{shRNA} / \mathrm{PDGF}-\mathrm{B}-\mathrm{HA} / \mathrm{DsRed}$ retrovirus effectively and rapidly induces gliomas in bi-transgenic mice and that this model provides an effective system in which to assess the effects of activating $d / n-A T F 5$ on tumor formation and maintenance.

\section{Induction of $d / n$-ATF5 prevents and eradicates/regresses gliomas}

We next queried whether induction of $\mathrm{d} / \mathrm{n}$-ATF5 (achieved by withdrawal of doxycycline) would affect tumor formation and maintenance. As noted above, a high proportion (32/34) of control animals without d/n-ATF5 expression formed malignant gliomas within 90-180 days post-injection with p53-shRNA/PDGF-BHA/DsRed retrovirus. This included bi-transgenic and wild-type mice continuously fed doxycycline, as well as hGFAP-tTA and pBi (III)-Flag-d/n-ATF5/LacZ monotransgenic mice either continuously treated with the drug, withdrawn from it following viral injection, or raised without the drug (Figure 5c). Of particular importance, for bi-transgenic animals treated with doxycycline, $14 / 14(100 \%)$ formed gliomas within 90150 days and $15 / 16(94 \%)$ by 180 days of viral treatment (Figure 5e).

We used two basic paradigms to monitor the effects of $\mathrm{d} / \mathrm{n}$-ATF5 on induced gliomas (Figure 5a). In the first, a 'prevention' paradigm, animals were withdrawn from doxycycline between 15 and 30 days before or on the day of injection with PDGF-B-HA/p53-shRNA/DsRed retrovirus and then assessed approximately 120-150 days later for tumor formation. Examination of the brains from bi-transgenic animals subjected to this paradigm revealed that only one of seven harbored a glioma (Figures 5d and e). This result contrasted with the $15 / 16$ bi-transgenic mice treated with doxycycline from conception that formed tumors within this time (Figure 5e). In the case of the one 'prevention paradigm' animal that formed a tumor, staining for $\mathrm{d} / \mathrm{n}$-ATF5 revealed that although this was expressed in the expected generative areas such as the SVZ, the tumor itself and surrounding areas did not have detectable $\mathrm{d} / \mathrm{n}$-ATF5 expression (data not shown). This suggests that the cells forming this tumor failed either to contain or to induce the $\mathrm{d} / \mathrm{n}$-ATF5 transgene.

In the second approach, a 'regression/eradication' paradigm, animals treated with doxycycline since conception were injected with the virus and maintained with the drug for an additional 90-120 days to permit tumor development and growth. As an indication that this time was sufficient for tumor formation, assessment of eight mice continuously raised with doxycycline until 90-95 days after retroviral injection revealed that all eight had formed gliomas (Figure 5e). After subjection to the initial tumor-forming period with doxycycline, a total of 24 mice were then withdrawn from the drug for approximately 40-60 days to allow drug clearance (14-21 days) and for potential regression/eradication of the pre-existing tumors. Analysis revealed that none of the 24 mice treated in this manner either exhibited moribund behavior up to the time of being killed or harbored detectable tumors (Figures 5b, d and e). This included eight mice that had been maintained for a total of 160-180 days after injection with the PDGF-B/p53- 
a
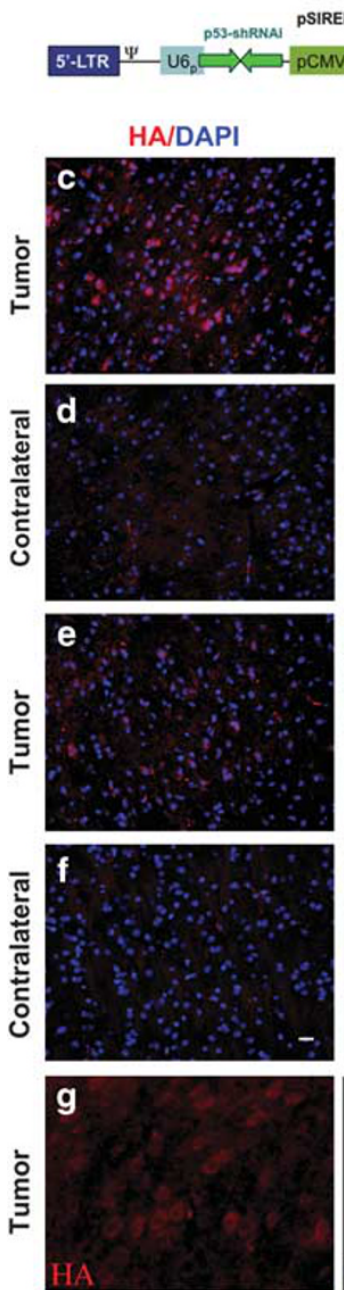

SIREN-RetroQ-DsRed-Express CMV
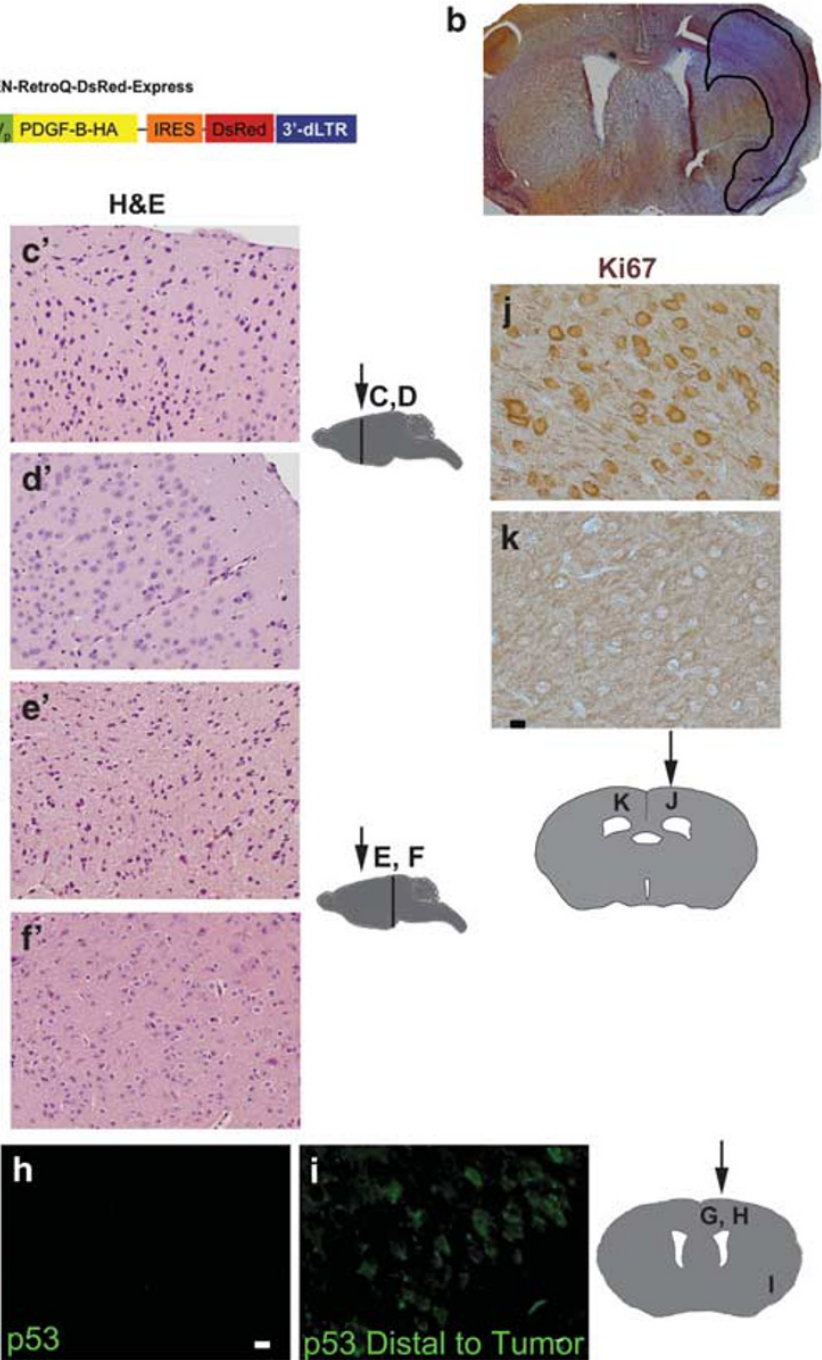

Figure 3 Retrovirus encoding PDGF-B-HA and p53-short hairpin RNA (shRNA) induces gliomas within mouse brains, and knocks down p53. (a) Scheme of self-inactivating retroviral construct used to induce gliomas. The $5^{\prime}$-long terminal repeat is intact, but the $3^{\prime}-$ deleted long terminal repeat possesses a deletion to prevent self-replication. The U6 pol III promoter drives transcription of p53-shRNA, whereas the cytomegalovirus promoter drives transcription of the bicistronic PDGF-B-HA-IRES-DsRed-Express reporter. (b) Frozen section. H\&E staining reveals a glioma induced in a doxycycline-treated hGFAP-tTA $\times$ pBi-TETO-3-Flag-d/n-ATF5/3-gal bitransgenic mouse 100 days after stereotactic injection of retrovirus expressing PDGF-B-HA and p53-shRNA. Area of glioma is enclosed within black line. $\left(\mathbf{c}, \mathbf{c}^{\prime}-\mathbf{f}, \mathbf{f}^{\prime}\right)$ Tumor cells induced by PDGF-B-HA/p53-shRNA express the HA tag and have dark hyperchromatic nuclei. The bi-transgenic mouse was continuously maintained with doxycycline from conception and was killed 135 days after injection with PDGF-B-HA/p53-shRNA retrovirus. Paraffin-embedded brain sections of PDGF-B-HA/p53-shRNA were immunostained with rabbit anti-HA antibody (red) and 4',6-diamidino-2-phenylindole (blue) (c-f) or H\&E $\left(\mathbf{c}^{\prime}-\mathbf{f}^{\prime}\right)$. $\mathbf{c}, \mathbf{c}^{\prime}$, e and $\mathbf{e}^{\prime}$ show PDGF-B-HA/p53shRNA-induced tumors, whereas $\mathbf{d}, \mathbf{d}^{\prime}, \mathbf{f}$ and $\mathbf{f}^{\prime}$ are from the corresponding tumor-free contralateral hemisphere. Scale bar $=12 \mu \mathrm{m}$. (g-i) Tumors induced by PDGF-B-HA/p53-shRNA express the HA tag, but not p53. Photos show immunostained (for HA and p53) paraffin-embedded brain sections from a bi-transgenic mouse continuously exposed to doxycycline from conception and killed 135 days after retroviral injection. The $\mathrm{HA}^{+}, \mathrm{p} 53^{-}$sections in (g) and (h) include tumor tissue, whereas the $\mathrm{p}^{+} 3^{+}$(green) section in (i) was outside the tumor margins. Scale bar $=5 \mu \mathrm{m}$. (j, k) Gliomas induced by PDGF-B-HA/p53-shRNA have a proliferative index of $100 \%$ calculated from Ki67 immunostaining. A monotransgenic hGFAP-tTA mouse was continuously fed with doxycycline from conception and killed 31 days after stereotactic injection with PDGF-B-HA/p53-shRNA retrovirus. Paraffin-embedded brain sections were immunostained for Ki67 antiserum with visualization by immunoperoxidase (brown). (j) $\mathrm{Ki}^{+} 7^{+}$cells in a glioma induced in the injected hemisphere, whereas (k) shows the absence of Ki67 staining in normal tissue in the contralateral hemisphere. Scale bar $=10 \mu \mathrm{m}$. Diagrams of brain sections in (c)-(k) show sites of retroviral injection (arrows) and corresponding areas where photographs were taken (vertical lines and letters). Diagrams are adapted from http://www.hms.harvard.edu/research/brain/atlas.

shRNA retrovirus (Figure 5e). This contrasted with 15/ 16 doxycycline-treated control bi-transgenic mice and $17 / 18$ monotransgenic or wild-type mice that formed tumors between 90 and 180 days after viral treatment and 6/16 doxycycline- and virus-treated control bi-transgenics that were judged to be moribund within this time frame (Figures $5 \mathrm{~b}-\mathrm{e}$ ).

The absence of tumors in mice in which $\mathrm{d} / \mathrm{n}$-ATF5 was induced was verified by examination of serial sections of frozen and paraffin-embedded brains stained 


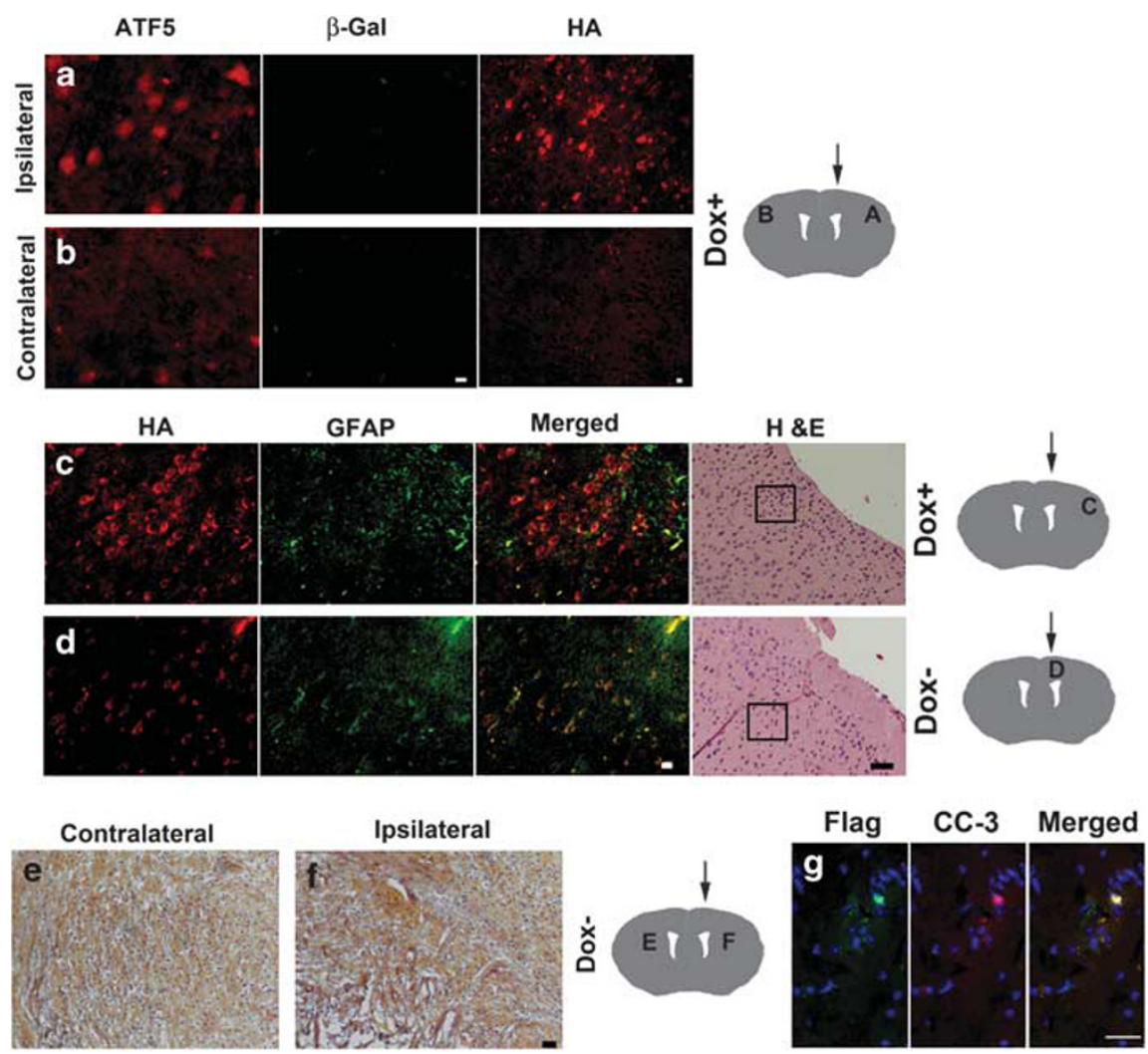

Figure 4 Bi-transgenic hGFAP-tTA $\times$ pBi-TETO-3-Flag-d/n-ATF5/ $\beta$-gal mice do not harbor detectable gliomas after induction of d/ n-ATF5. (a, b) PDGF-B-HA/p53-shRNA-induced glioma in a bi-transgenic mouse expresses ATF5, but not the $d / n$-ATF5/ $/$-gal transgene. The mouse was continuously maintained on doxycycline from conception to suppress d/n-ATF5 induction and was killed 135 days post-stereotactic injection with PDGF-B-HA/p53-shRNA retrovirus. Brain sections were stained with rabbit anti-ATF5 antibody (red) and chicken anti- $\beta$-gal antibody (green). Note strong immunostaining for ATF5 and lack of $\beta$-gal immunostaining in tumor (a) and only weak scattered, low-level ATF5 immunoreactivity in the contralateral hemisphere (b). H\&E staining for (a) is from the same brain shown in Figure $3 \mathrm{c}^{\prime}$, and $\mathrm{H} \& \mathrm{E}$ staining for $(\mathbf{b})$ is from the same brain shown in Figure $3 \mathrm{~d}^{\prime}$. Scale bar $=6 \mu \mathrm{m}$. (c, d) Immunostaining for the HA tag (red) and GFAP (green) detects a glioma, as shown by H\&E staining, in a mouse in which expression of d/n-ATF5 was suppressed (c), but not in a mouse in which d/n-ATF5 was induced (d). The right-hand panels show H\&E staining to confirm the presence or absence of a glioma. Boxes within the H\&E photos show where the anti-HA and anti-GFAP immunofluorescence images were taken. Scale bar $=40 \mu \mathrm{m}$ for H\&E photos and $12 \mu \mathrm{m}$ for immunofluorescence images in (c) and (d). The bi-transgenic mouse in (c) was continuously maintained on doxycycline from conception to suppress d/n-ATF5 induction and was killed 135 days post-stereotactic injection with PDGF-B-HA/p53-shRNA retrovirus. Note HA and GFAP immunostaining in tumor remote from site of injection (c). The bi-transgenic mouse in (d) was maintained on doxycycline from conception to 90 days postinjection with PDGF-B-HA/p53-shRNA retrovirus. Doxycycline was then withdrawn from the diet for 45 days to induce d/n-ATF5 and the animal was killed. Examination of serial brain sections revealed scattered HA-stained cells as shown, only at the site of viral injection. $\mathrm{GFAP}^{+}$cells at upper right reflect astrocytic activation in response to the injection wound. Paraffin-embedded sections. (e, f) Evidence for eradication of a pre-existing tumor by induction of $\mathrm{d} / \mathrm{n}$-ATF5. The bi-transgenic mouse was maintained on doxycycline from conception to 92 days post-injection with PDGF-B-HA/p53-shRNA retrovirus. Doxycycline was then withdrawn from the diet for 50 days to induce d/n-ATF5. (e) Normal cells in contralateral hemisphere, but (f) lesions in the neutrophil remote from the viral injection site in the ipsilateral hemisphere. Scale bar $=20 \mu \mathrm{m}$. (g) Co-expression of cleaved caspase-3 (CC-3) and d/nATF5 in a tumor remnant in the 'eradication/regression' paradigm. A bi-transgenic mouse was maintained on doxycycline from conception to 90 days after injection with PDGF-B-HA/p53-shRNA retrovirus. Doxycycline was then withdrawn from the diet for 50 days to induce d/n-ATF5 and the animal was killed. Brain sections that contained a remnant of a glioma were co-stained for Flagtagged d/n-ATF5 (green) and cleaved-caspase-3 (red). Scale bar $=20 \mu \mathrm{m}$. Diagrams show the brain areas for stereotactic injection site (arrow) with corresponding panel letter (diagrams adapted from http://www.hms.harvard.edu/research/brain/atlas).

with $\mathrm{H} \& \mathrm{E}$ as well as by immunohistochemistry for GFAP, HA (to detect virally delivered PDGF-B-HA), and DsRed (also to detect retroviral infection), Ki67 and ATF5. In these tumor-free mice, staining for HA and DsRed, when present, was confined to cells (many of which were $\mathrm{GFAP}^{+}$) in the area of the viral injections and did not show the cellular density, invasiveness or morphology typical of gliomas (Figure 4d). In about half of the animals, H\&E staining showed architectural disruption and lesions that were confined to the virally injected hemisphere, suggestive of the previous presence of tumors (Figures $4 \mathrm{e}$ and f). In one case, we co-stained the apparent remnants of a regressed/eradicated tumor for Flag-tagged-d/n-ATF5 ${ }^{+}$and cleaved caspase- 3 . This revealed a small number of co-stained cells indicating that induction of $\mathrm{d} / \mathrm{n}$-ATF5 promoted death of tumor cells by an apoptotic mechanism (Figure 4g). Otherwise, induction of $\mathrm{d} / \mathrm{n}$-ATF5 showed no evident damage to normal brain tissue in the injected and contralateral hemispheres. The persistence of apparently non-trans- 
a

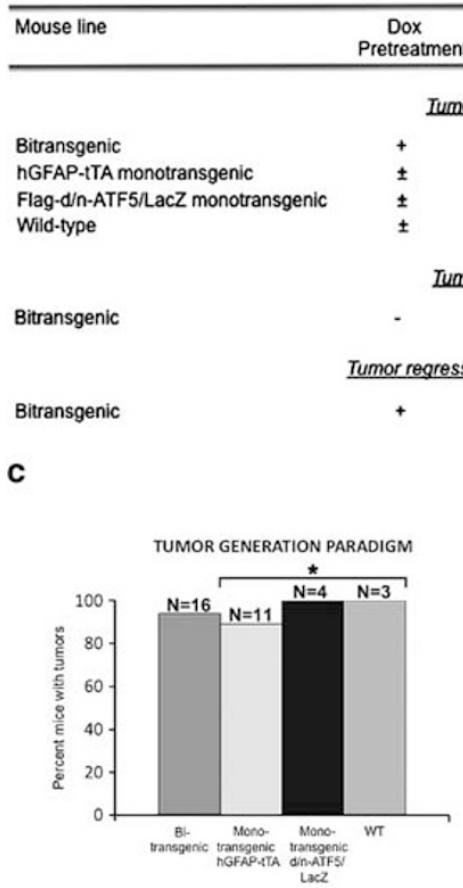

b

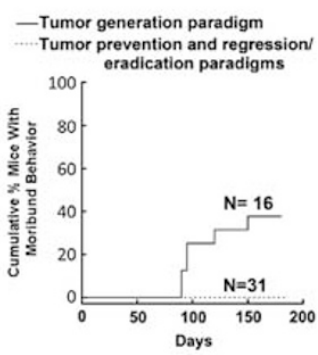

d

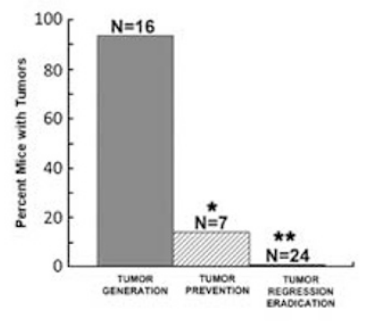

e $=$ Tumor generation paradigm (+dox) Tumor prevention paradigm (-dox) paradigm (+dox $\rightarrow$ dox $)$
par regression/eradication

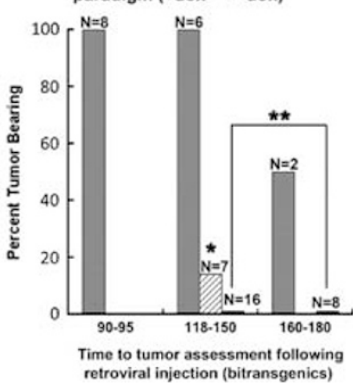

Figure 5 Induction of d/n-ATF5 in pBi3-Flag-d/n-ATF5/LacZ $\times$ hGFAP-tTA bi-transgenic mice blocks formation and causes regression/eradication of gliomas induced by PDGF-B-HA/p53-shRNA. (a) Overview of experimental approach to testing the effect of $\mathrm{d} / \mathrm{n}$-ATF5 on glioma generation and regression/eradication in mice. (b) Moribund behavior in bi-transgenic mice injected with retrovirus expressing PDGF-B-HA/p53-shRNA and its prevention by induction of d/n-ATF5 in the glioma prevention and regression/ eradication paradigms. Data show cumulative percentage of injected mice judged by veterinary staff to have moribund behavior as a function of time after viral injection. All mice found to exhibit moribund behavior were immediately killed and all were found to be tumor bearing. (c) Gliomas are induced with high efficiency in mice in which d/n-ATF5 is not expressed. Data show percentage of glioma formation in response to cerebral injection with PDGF-B-HA/p53-shRNA retrovirus in bi-transgenic (all treated with doxycycline from conception), monotransgenic hGFAP-tTA (three treated with doxycycline from conception, six treated with doxycycline from conception and withdrawn from the drug after viral injection, and two raised entirely without doxycycline), monotransgenic Flag-d/n-ATF5/LacZ (one treated with doxycycline from conception, one treated with doxycycline from conception and withdrawn from the drug after viral injection and two raised entirely without doxycycline) and wild-type (WT) (all treated with doxycycline from conception) mice. $N$ indicates numbers of animals in each group. *Bi-transgenic mice versus monotransgenic mice, no statistical difference $(P=1.0)$. (d) Induction of $\mathrm{d} / \mathrm{n}$-ATF5 suppresses generation of new gliomas and causes regression/eradication of pre-existing gliomas. Percent bi-transgenic mice with detectable gliomas is shown for the three treatment paradigms described in (a) and in the text and Materials and methods. The doxycycline-treated bi-transgenic mice in the 'tumor generation' paradigm are those described in (b). $N$ indicates numbers of animals in each group. ${ }^{*}$ Bi-transgenic Dox ${ }^{+}$versus bi-transgenic prevention Dox ${ }^{-}, P=0.0005$; **bi-transgenic Dox ${ }^{+}$versus bi-transgenic Dox ${ }^{-}$regression/eradication, $P=4 \times 10^{-10}$. (e) Percentage of bi-transgenic mice with tumors at different times of assessment after injection with PDGF-B-HA/p53-shRNA retrovirus and subjected to the three treatment paradigms described in (a). Between 118 and 180 days. ${ }^{*}$ Bi-transgenic Dox ${ }^{+}$versus bi-transgenic prevention Dox $^{-}, P=0.01$; **bi-transgenic Dox $^{+}$versus bi-transgenic Dox ${ }^{-}$regression/eradication, $P=0.000002$. Animals are those described in panels $\mathbf{c}$ and $\mathbf{d}$. $N$ indicates the number of animals assessed in each group at each time.

formed $\mathrm{HA}^{+} / \mathrm{GFAP}^{+}$cells at the site of viral injection (Figure 4d) is consistent with this interpretation.

\section{Discussion}

The aim of this study was to determine whether induction of d/n-ATF5 in mouse brain cells could block the de novo formation of gliomas and could cause the regression/eradication of pre-existing tumors. This approach was highly effective in both scenarios with no evident harmful effect on surrounding normal brain tissue.

We took advantage of a previously described model in which neural progenitor/stem cells are efficiently transformed by influx of PDGF-A homodimer ligand or by infection with PDGF-B retrovirus (Assanah et al., 2006, 2009; Jackson et al., 2006). This is in line with reports that neural progenitor cells in the SVZ and oligodendrocyte precursors in the corpus callosum express PDGF-A receptors (Canoll and Goldman, 2008). The resulting tumors highly resemble human glioblastomas and oligodendromas (Uhrbom et al., 1998, 2000; Dai et al., 2001; Shih et al., 2004). We additionally used co-delivery of p53-shRNA to accelerate the efficiency of tumor formation (Hesselager et al., 2003).

Past work has established that human glioblastomas invariably appear to express ATF5 (Dong et al., 2005; Angelastro et al., 2006; Monaco et al., 2007; Sheng et al., 2010) and that the level of expression correlates 
with disease prognosis (Dong et al., 2005; Sheng et al., 2010). Here, we also found that PDGF-B/p53-shRNAinduced mouse gliomas also express high levels of ATF5. In addition, multiple independent cell lines derived from human and rodent glioblastomas express ATF5 (Angelastro et al., 2006) and we have shown that ATF5 small interfering RNA and $\mathrm{d} / \mathrm{n}$-ATF5 cause massive apoptotic death of all tested human and rat glioblastoma cell lines in culture. In addition, retrovirally delivered $\mathrm{d} / \mathrm{n}$-ATF5 also induces high-efficiency death of glioblastoma cells formed in rat brain from injected C6 glioblastoma cells (Angelastro et al., 2006). These studies have significantly extended such work to a de novo malignant glioma model in adult animals and have established that $\mathrm{d} / \mathrm{n}$-ATF5 very effectively blocks both generation and maintenance of such tumors in vivo. In the tumor 'prevention' paradigm, only $1 / 7$ animals formed detectable gliomas as compared with 14/14 control animals over the same time period. For the one animal in the 'prevention' paradigm that did form a glioma, expression of $\mathrm{d} / \mathrm{n}$-ATF5 was absent from the tumor. In the 'regression/eradication' paradigm, none of the 24 animals formed tumors and none showed moribund behavior. This included eight animals maintained up to 160-180 days after viral treatment. In contrast, 15/16 control bi-transgenic animals (in which d/n-ATF5 expression was suppressed) formed gliomas within 180 days or less and 6/16 of which had to be killed owing to moribund behavior.

Although we did not image animals to verify tumor formation before inducing $\mathrm{d} / \mathrm{n}-\mathrm{ATF} 5$ in the 'regression/ eradication' paradigm, our findings strongly support the likelihood that the animals had developed gliomas by this time. In our study, virally treated animals were maintained with doxycycline for 90-120 days before $\mathrm{d} / \mathrm{n}$-ATF5 induction. This should have provided ample time for tumors to form. For example, for doxycyclinetreated bi-transgenic mice, 8/8 examined between 90-95 days after viral treatment had formed gliomas. On the basis of the high proportion of animals that formed tumors when d/n-ATF5 was not induced (32/34; 94\%), it also appears highly likely that most of the animals in the 'regression/eradication' paradigm would have formed tumors by the time that $\mathrm{d} / \mathrm{n}$-ATF5 was induced. Such findings predict that $21-23$ of the 24 animals in the 'regression/eradication' paradigm would have formed tumors and that the probability that none of the 24 would have formed tumors is $P<1.0 \times 10^{-8}$ (Fisher's exact test). Furthermore, the presence of architectural disruptions in brains of about half of the d/n-ATF5expressing mice in the 'regression/eradication' paradigm further supports the previous formation of tumors.

One question that our study did not entirely address and that remains to be determined is whether induction of $\mathrm{d} / \mathrm{n}$-ATF5 fully eradicates tumors or whether it causes them to regress to an undetectable size that will ultimately grow back over a longer period of time than covered in our experiments. It also remains to be determined whether tumors will return upon retreatment with doxycycline to suppress $d / n-A T F 5$ expression. Past studies indicate that tumor stem cells express
ATF5 (Schrot et al., 2007; Sheng et al., 2010), which raises the possibility that $\mathrm{d} / \mathrm{n}$-ATF5 may interfere with this potential source of tumor regrowth and expansion.

The precise mechanism by which $\mathrm{d} / \mathrm{n}$-ATF5 blocks glioma formation or maintenance in our in vivo model remains to be fully investigated. Our earlier studies showed that $\mathrm{d} / \mathrm{n}$-ATF5 expression and ATF5-small interfering RNA interference lead to massive caspasedependent apoptosis of cultured glioblastoma cell lines (Angelastro et al., 2006). Likewise, breast cancer cell lines exhibited condensed or fragmented chromatin, indicative of apoptosis, after the expression of $\mathrm{d} / \mathrm{n}$ ATF5 (Monaco et al., 2007). Consistent with this, in this, we detected co-expression of cleaved caspase- 3 and FLAG-d/n-ATF5 in the remnant of a tumor in an animal in which $d / n-A T F 5$ had been induced. Although interference with ATF5 function causes cell cycle exit in cells such as activated astrocytes and neuroprogenitor cells (Angelastro et al., 2006), it did not do so in the case of cultured glioblastoma cells (Angelastro et al., 2006) or of HeLa or FL5.12 cells (Persengiev et al., 2002), and so it seems highly likely that the elimination at least of pre-existing gliomas by $\mathrm{d} / \mathrm{n}$-ATF5 is due to active promotion of cell death rather than to stasis. The induction of p53 can be an effective means to block tumor progression; however, in our tumor eradication experiments, p53 expression was suppressed in the induced gliomas by p53-shRNA. Also, in cultured glioblastoma lines, the capacity of $\mathrm{d} / \mathrm{n}$-ATF5 or ATF5 small interfering RNA to cause apoptotic death was independent of whether the cells had intact or deficient p53 signaling (Angelastro et al., 2006).

The current literature identifies several ATF5-responsive genes with the potential to have roles in glioma cell survival and death. These include heat-shock protein 27 (Wang et al., 2007), which can protect neoplastic cells from apoptosis (Concannon et al., 2001, 2003; Garrido et al., 2003; Elstrand et al., 2009), EGR-1 (Li et al., 2009), which is reported to govern both cell survival and death (Thiel and Cibelli, 2002), the anti-apoptotic myeloid cell leukemia sequence-1 (MCL1) gene (Sheng et al., 2010) as well as the anti-apoptotic Bcl-2 gene (Dluzen et al., 2011). Our model system is amenable to testing these and other potential ATF5-regulated genes for their roles in glioma survival and death.

An important feature of our findings was that while d/n-ATF5 blocked formation of and eliminated gliomas, it had no evident harmful effects on normal brain tissue. There were no evident behavioral changes in animals with long-term $\mathrm{d} / \mathrm{n}$-ATF5 induction and brain structure appeared to be normal with the exception of an apparent mild enlargement of the lateral ventricles. We also failed to detect cleaved caspase- 3 in any non-tumor cells in which $\mathrm{d} / \mathrm{n}-\mathrm{ATF} 5$ was induced. As in our previous studies of embryonic and neonatal brain (Angelastro et al., 2003, 2005), ATF5 expression in post-natal mouse brain appeared to be mainly limited to neurogenic zones and to scattered glial precursors and absent from post-mitotic neurons. In our past work, we found that $\mathrm{d} / \mathrm{n}-\mathrm{ATF} 5$ caused premature cell cycle exit and differentiation of neuroprogenitors and glial 
precursors, but did not appear to affect their survival either in vitro or in vivo (Angelastro et al., 2005; Mason et al., 2005). We also noted that ATF5 is re-expressed in astrocytes that were stimulated to proliferate by serial passage in culture (Angelastro et al., 2006). Although d/n-ATF5 caused such cells to exit the cycle, it did not promote their death. In this study, we also observed the long-term survival of normal GFAP ${ }^{+}$cells in which $\mathrm{d} / \mathrm{n}$ ATF5 had been induced. In addition, while d/n-ATF5 caused death of multiple breast cancer cell lines, it was without effect on survival of non-transformed breast cell lines (Monaco et al., 2007). Taken together, current findings thus indicate that interference with ATF5 function appears to spare the survival of normal brain (and at least some other) tissues while leading to the death of transformed glioma and breast cancer cells.

The one phenotypic response that we observed in animals with long-term induction of d/n-ATF5 was an apparent mild enlargement of the lateral ventricles. This could be due to enhanced differentiation of neural progenitors in the neurogenic niches along the lateral ventricles into neurons and glia as seen in our embryonic studies (Angelastro et al., 2003, 2005), and/or to inhibited proliferation of such cells. Although reduction of adult neuroprogenitor cell numbers may conceivably influence cognition and/or mood (Santarelli et al., 2003; David et al., 2009), the indications that d/n-ATF5 is not lethal for normal neuroprogenitor cells and has static actions on activated astrocytes raises the testable possibility that its effects on these populations may be readily reversible.

Our observation that $\mathrm{d} / \mathrm{n}$-ATF5 causes effective regression/eradication of induced gliomas supports the idea of targeting ATF5 to treat human glioblastomas. This is bolstered by the apparent universal expression of ATF5 in human gliomas (Dong et al., 2005; Angelastro et al., 2006; Monaco et al., 2007; Sheng et al., 2010) and by the effectiveness of interfering with ATF5 function on promoting death of a wide variety of glioma cell lines (Angelastro et al., 2006). Although targeting transcription factors is often considered as especially challenging, several potential routes to this end are conceivable. For instance, one approach would be to design pharmaceutical inhibitors of ATF5 function based on its structural properties. Significant progress has been made towards expressing, refolding and structurally characterizing the ATF5 bZip domain with this end in mind (Ciaccio et al., 2008; Ciaccio and Laurence, 2009). Another approach would be to target the pathway(s) responsible for ATF5 expression in gliomas. The human ATF5 promoter has been described (Wei et al., 2010) and a recent genomewide RNA interference screen identified a RAS/MAPK/ PI3K/CREB3L2 signaling pathway responsible for ATF5 expression in glioma cells (Sheng et al., 2010). Significantly, interference with this pathway by the RafK inhibitor sorafenib inhibits ATF5 expression and glioma growth in vitro and inhibited tumor formation in a mouse orthotopic glioma model (Sheng et al., 2010). A third approach would be to target downstream targets of ATF5 responsible for tumor survival such as the heatshock protein 27, EGR-1, MCL-1 and Bcl-2 described above. Finally, the findings regarding the efficacy of $d / n-$ ATF5 in causing regression/eradication of malignant gliomas through an interfering peptide (based on the sequence of d/n-ATF5) would be a potential therapy for glioblastomas, delivered either systemically or locally within the brain. Preliminary experiments with a cellpenetrant form of $d / n$-ATF5 lead us to believe that this approach is both feasible and effective.

\section{Materials and methods}

\section{Animals}

Flag-tagged-NT-Azip-ATF5 (d/n-ATF5) was subcloned into the Not 1 and Sal1 sites of the bi-directional TETO (pBiTETO-3) vector. The TETO element has one cytomegalovirus minimum promoter on each end. Thus, the pBI-3 vector expresses the $\mathrm{d} / \mathrm{n}$-ATF5 on one side of the TETO promoter, whereas LacZ ( $\beta$-gal) is expressed at the opposite side of the promoter (Baron et al., 1995). Pronuclear microinjection of the linearized pBiTETO-d/n-ATF5 construct into B6CBA/F1 mouse embryos created two founder mice (Columbia University, New York, NY, USA). One pBiTETO-d/n-ATF5 transgenic $\mathrm{B} 6 \mathrm{CBA} / \mathrm{F} 1$ mouse was able to transmit the transgene, and a new mouse line was established. Two male TETO-d/n-ATF5 ${ }^{-/+}$mice were shipped to the University of California Davis Mouse Biology Program, rederived and backcrossed seven generations into a C57BL/6J background.

C57BL/6J male mice with the hGFAP-tTA transgene were kindly provided by Dr Kenneth McCarthy, University of North Carolina Chapel Hill (Chapel Hill, NC, USA) (10 generations C57BL/6 backcrossed). The hGFAP-tTA mice were rederived into C57BL/6J background at University of California Davis (Davis, CA, USA). TETO-d/n-ATF5 ${ }^{-/+}$male mice were bred with homozygous hGFAP-tTA $+/+$ C57BL/6J female mice to produce litters with $50 \%$ bi-transgenic offspring. Monogenic TETO-d/n-ATF5 $5^{-/+}$mice were produced by breeding TETO-d/n-ATF5 $5^{-/+}$with heterozygous hGFAP-tTA ${ }^{-/+}$ mice. The hGFAP-tTA female mice were routinely harem bred with one TETO-d/n-ATF5 ${ }^{-1+}$ male to minimize genetic variability. Doxycycline $(200 \mathrm{mg} / \mathrm{kg}$; Bio-Serve, Frenchtown, NJ, USA) was administrated in the chow to inhibit transgene expression, where indicated. The Institutional Animal Care and Use Committee approved mouse protocol (13026) according to strict Institutional Animal Care and Use Committee regulations and guidelines at the University of California Davis and the National Institutes of Health.

\section{Stereotactic viral injection and killing of animals}

Adult mice were anesthetized with $2 \%$ isoflurane/oxygen mixture. The fur on top of their heads was shaved to expose the skin for surgical incision. The mice were then placed into the stereotactic apparatus with continuous flow of isoflurane $(2-5 \%)$ and oxygen. The scalps were sagittally incised to expose the skull, and a $1 \mathrm{~mm}$ burr hole was drilled in the skull. A Hamilton syringe vertically attached to the apparatus injected $1.0-1.8 \mu 1$ of Dulbecco's modified Eagle's medium containing 100 PDGF-B HA/p53-shRNA/DsRed or p53-shRNA/DsRed Express retroviral particles per $\mathrm{ml}(0.2 \mu \mathrm{l} / \mathrm{min})$ at stereotactic coordinates (relative to Bregma) $1.0 \mathrm{~mm}$ anterior, $1.0 \mathrm{~mm}$ lateral and at a depth of $2.3 \mathrm{~mm}$ from the skull. The scalps were closed with Vetbond tissue adhesive and the mice were then injected intraperitoneally with carporfen $(5 \mathrm{mg} / \mathrm{kg})$. The animals were monitored throughout the following period, which varied from 40 to 180 days. The mice were killed by intraperitoneal injection of ketamine (intraperitoneally at 
$80-100 \mathrm{mg} / \mathrm{kg}$ ) and xylazine (intraperitoneally at $5-10 \mathrm{mg} / \mathrm{kg}$ ), or by deep isoflurane/oxygen anesthesia followed by cervical dislocation or transcardiac perfusion with $0.9 \% \mathrm{NaCl}$.

\section{Tissue preparation}

Mouse brains harvested after being killed were washed in phosphate-buffered saline, fixed in $4 \%$ paraformaldehyde and incubated overnight in $30 \%$ sucrose. The brains were then mounted in OCT media, frozen and cut into $14-\mu \mathrm{m}$ coronal sections. Alternatively, perfused brains were fixed in $10 \%$ formalin and then embedded in paraffin. Paraffin blocks were cut as $5-\mu \mathrm{m}$ sections. The paraffin sections were subjected to antigen retrieval as described (Schrot et al., 2007). Slides containing sections were stained with antibodies for the following: $\beta$-gal (LacZ: Abcam, Cambridge, MA, USA; 1:1000), mouse GFAP (1:500), mouse nestin (1:500) and rabbit anti-Musashi (1:500) (Millipore, Billerica, MA, USA). Anti-Flag M2 (1:200) and 4',6-diamidino-2-phenylindole were from Sigma-Aldrich (St Louis, MO, USA). Mouse anti-p53 C12 (1:1000) and rabbit anti-cleaved caspase-3 (1:1600) were from Cell Signaling (Danvers, MA, USA); rabbit anti-HA $(4 \mu \mathrm{g} / \mathrm{ml}$; sc- 805$)$ was from Santa Cruz Biotechnology (Santa Cruz, CA, USA); rabbit anti-PDGF-A receptor was from Spring Bioscience (Pleasanton, CA, USA); and rabbit anti-Ki67 (1:1000) was from Leica Microsystems Inc. (Buffalo Grove, IL, USA). Rabbit antiATF5 antiserum was used at 1:500 (Angelastro et al., 2006). Sections were then visualized with immunofluorescence (Alexa 488/568; Invitrogen, Eugene, OR, USA) or colorimetrically with diaminobenzidine or fast red (Mach2; Biocare Medical, Concord, CA, USA) and photographed on a Carl Zeiss Axiovert 200 with Axiocam video capture or with Olympus FV-1000 confocal microscope and the Fluoview software.

\section{Tumor detection}

Assessment for brain tumors was achieved through examination of sequential serial sections from each brain. Gliomas were detected using 4',6-diamidino-2-phenylindole and $\mathrm{H} \& \mathrm{E}$ staining and were observed as diffuse infiltrative hyperchromatic high-density cells with atypical nuclei. In areas where gliomas occupied the cortex, neurons were greatly reduced in number. All brains were immunostained with anti-GFAP. There was an increase in GFAP staining in regions where tumors developed. In addition, all brains were immunostained with anti- $\beta$-gal. In all cases there was no detectable $\beta$-gal signal in doxycycline ${ }^{+}$brains, but all doxycycline $e^{-}$brains showed detectable $\beta$-gal. For further identification of tumor cells, we immunostained a subset of brains with anti-HA, anti-Ki67 and
anti-PDGFR-A, and anti-ATF5 markers. All tumors were immunopositive for all of the markers. Detection with DsRed was also immunoreactive in the tumors, but not in normal cells. Similar results were found in both paraffin-embedded brains $(13 \%$ of total) and frozen brains (87\% of total). A veterinary neuropathologist $(\mathrm{RJH})$ examined $21 \%$ of the total brains to confirm the presence and absence of tumor cells.

\section{Statistical analysis}

A $2 \times 2$ contingency table was generated to determine the likelihood ratio test statistic using the Fisher's exact test (http://www.matforsk.no/ola/fisher.htm).

\section{Conflict of interest}

Columbia University, on behalf of inventors Drs Angelastro and Greene, has been awarded a United States patent (no.7888326 B2) for use of ATF5 inhibitors to promote death of neoplastic cells. Dr Luca Santarelli is currently a full-time employee of F Hoffmann-La Roche Ltd. However, his contributions to this work were completed before his employment relationship with F Hoffmann-La Roche Ltd. Drs AA, MWLé and RH declare no potential conflict of interest.

\section{Acknowledgements}

This work was supported in part by NIH Grant NS-33689 and an award from the Alexander and Margaret Stewart Trust (to LAG); NIH-NCI F31 CA123711-01A1 (to ADA); and in part support of the UCD Cancer Center Support Grant 5P30CA093373-06S1 (to JMA) and in full NIH-NCI R21CA126924 (to JMA). We thank Benjamin Pyles for his technical assistance in management of the mouse colony, genotyping, surgeries and anesthesia, as well as planning experimental end points. We thank Dr Stephen Noctor for the use of the Olympus FV-1000 confocal microscope and Fluoview software. We are indebted to Dr Robert Higgins (Neuropathologist, DVM/PhD) for assessment and evaluation of gliomas in mice with and without induced expression of d/n-ATF5.

Author contributions: Conceived and designed the experiments: ADA, MWL, LS, RH, LAG, JMA. Performed the experiments: ADA, MWL, JMA. Analyzed the data: ADA, MWL, LAG, LS, JMA. Contributed reagents/materials/analysis tools: RH, LS, LAG. Wrote the paper: ADA, LAG, JMA.

\section{References}

Alvarez-Buylla A, Lim DA. (2004). For the long run: maintaining germinal niches in the adult brain. Neuron 41: 683-686.

Angelastro JM, Canoll PD, Kuo J, Weicker M, Costa A, Bruce JN et al. (2006). Selective destruction of glioblastoma cells by interference with the activity or expression of ATF5. Oncogene 25: 907-916.

Angelastro JM, Ignatova TN, Kukekov VG, Steindler DA, Stengren GB, Mendelsohn C et al. (2003). Regulated expression of ATF5 is required for the progression of neural progenitor cells to neurons. J Neurosci 23: 4590-4600.

Angelastro JM, Mason JL, Ignatova TN, Kukekov VG, Stengren GB, Goldman JE et al. (2005). Downregulation of activating transcription factor 5 is required for differentiation of neural progenitor cells into astrocytes. J Neurosci 25: 3889-3899.

Assanah M, Lochhead R, Ogden A, Bruce J, Goldman J, Canoll P. (2006). Glial progenitors in adult white matter are driven to form malignant gliomas by platelet-derived growth factor-expressing retroviruses. J Neurosci 26: 6781-6790.

Assanah MC, Bruce JN, Suzuki SO, Chen A, Goldman JE, Canoll P. (2009). PDGF stimulates the massive expansion of glial progenitors in the neonatal forebrain. Glia 57: 1835-1847.

Baron U, Freundlieb S, Gossen M, Bujard H. (1995). Co-regulation of two gene activities by tetracycline via a bidirectional promoter. Nucleic Acids Res 23: 3605-3606.

Canoll P, Goldman JE. (2008). The interface between glial progenitors and gliomas. Acta Neuropathol 116: 465-477.

Ciaccio NA, Laurence JS. (2009). Effects of disulfide bond formation and protein helicity on the aggregation of activating transcription factor 5. Mol Pharm 6: 1205-1215.

Ciaccio NA, Moreno ML, Bauer RL, Laurence JS. (2008). Highyield expression in $E$. coli and refolding of the bZIP domain 
of activating transcription factor 5. Protein Expr Purif 62: 235-243.

Concannon CG, Gorman AM, Samali A. (2003). On the role of Hsp27 in regulating apoptosis. Apoptosis 8: 61-70.

Concannon CG, Orrenius S, Samali A. (2001). Hsp27 inhibits cytochrome $c$-mediated caspase activation by sequestering both pro-caspase-3 and cytochrome $c$. Gene Expr 9: 195-201.

Dai C, Celestino JC, Okada Y, Louis DN, Fuller GN, Holland EC. (2001). PDGF autocrine stimulation dedifferentiates cultured astrocytes and induces oligodendrogliomas and oligoastrocytomas from neural progenitors and astrocytes in vivo. Genes Dev 15: 1913-1925.

Dai C, Holland EC. (2001). Glioma models. Biochim Biophys Acta 1551: M19-M27.

David DJ, Samuels BA, Rainer Q, Wang JW, Marsteller D, Mendez I et al. (2009). Neurogenesis-dependent and -independent effects of fluoxetine in an animal model of anxiety/depression. Neuron 62: 479-493.

Dluzen D, Li G, Tacelosky D, Moreau M, Liu DX. (2011). Bcl-2 is a downstream target of ATF5 that mediates ATF5' pro-survival function in a cell type-dependent manner. $J$ Biol Chem 286: 7705-7713.

Dong S, Nutt CL, Betensky RA, Stemmer-Rachamimov AO, Denko NC, Ligon KL et al. (2005). Histology-based expression profiling yields novel prognostic markers in human glioblastoma. J Neuropathol Exp Neurol 64: 948-955.

Elstrand MB, Kleinberg L, Kohn EC, Trope CG, Davidson B. (2009). Expression and clinical role of antiapoptotic proteins of the bag, heat shock, and $\mathrm{Bcl}-2$ families in effusions, primary tumors, and solid metastases in ovarian carcinoma. Int J Gynecol Pathol 28: $211-221$.

Fiacco TA, Agulhon C, Taves SR, Petravicz J, Casper KB, Dong X et al. (2007). Selective stimulation of astrocyte calcium in situ does not affect neuronal excitatory synaptic activity. Neuron $\mathbf{5 4}$ : 611-626.

Garrido C, Schmitt E, Cande C, Vahsen N, Parcellier A, Kroemer G. (2003). HSP27 and HSP70: potentially oncogenic apoptosis inhibitors. Cell Cycle 2: 579-584.

Ghashghaei HT, Weimer JM, Schmid RS, Yokota Y, McCarthy KD, Popko B et al. (2007). Reinduction of ErbB2 in astrocytes promotes radial glial progenitor identity in adult cerebral cortex. Genes Dev 21: $3258-3271$.

Gossen M, Bonin AL, Freundlieb S, Bujard H. (1994). Inducible gene expression systems for higher eukaryotic cells. Curr Opin Biotechnol 5: $516-520$.

Gossen M, Bujard H. (1992). Tight control of gene expression in mammalian cells by tetracycline-responsive promoters. Proc Natl Acad Sci U S A 89: 5547-5551.

Greene LA, Lee HY, Angelastro JM. (2009). The transcription factor ATF5: role in neurodevelopment and neural tumors. $J$ Neurochem 108: $11-22$.

Hede SM, Hansson I, Afink GB, Eriksson A, Nazarenko I, Andrae J et al. (2009). GFAP promoter driven transgenic expression of PDGFB in the mouse brain leads to glioblastoma in a Trp53 null background. Glia 57: 1143-1153.

Hesselager G, Uhrbom L, Westermark B, Nister M. (2003). Complementary effects of platelet-derived growth factor autocrine stimulation and p53 or Ink4a-Arf deletion in a mouse glioma model. Cancer Res 63: 4305-4309.

Jackson EL, Alvarez-Buylla A. (2008). Characterization of adult neural stem cells and their relation to brain tumors. Cells Tissues Organs 188: 212-224.

Jackson EL, Garcia-Verdugo JM, Gil-Perotin S, Roy M, QuinonesHinojosa A, VandenBerg S et al. (2006). PDGFR alpha-positive B cells are neural stem cells in the adult SVZ that form gliomalike growths in response to increased PDGF signaling. Neuron 51: 187-199.

Krylov D, Olive M, Vinson C. (1995). Extending dimerization interfaces: the bZIP basic region can form a coiled coil. EMBO J 14: 5329-5337.
Li G, Li W, Angelastro JM, Greene LA, Liu DX. (2009). Identification of a novel DNA binding site and a transcriptional target for activating transcription factor 5 in c6 glioma and mcf-7 breast cancer cells. Mol Cancer Res 7: 933-943.

Mason JL, Angelastro JM, Ignatova TN, Kukekov VG, Lin G, Greene LA et al. (2005). ATF5 regulates the proliferation and differentiation of oligodendrocytes. Mol Cell Neurosci 29: $372-380$.

Moitra J, Mason MM, Olive M, Krylov D, Gavrilova O, MarcusSamuels B et al. (1998). Life without white fat: a transgenic mouse. Genes Dev 12: 3168-3181.

Moll JR, Olive M, Vinson C. (2000). Attractive interhelical electrostatic interactions in the proline- and acidic-rich region (PAR) leucine zipper subfamily preclude heterodimerization with other basic leucine zipper subfamilies. J Biol Chem 275: 34826-34832.

Monaco SE, Angelastro JM, Szabolcs M, Greene LA. (2007). The transcription factor ATF5 is widely expressed in carcinomas, and interference with its function selectively kills neoplastic, but not nontransformed, breast cell lines. Int J Cancer 120: 1883-1890.

$\mathrm{Mu}$ Y, Lee SW, Gage FH. (2010). Signaling in adult neurogenesis. Curr Opin Neurobiol 20: 416-423.

Ogden AT, Waziri AE, Lochhead RA, Fusco D, Lopez K, Ellis JA et al. (2008). Identification of A2B5+CD133 - tumor-initiating cells in adult human gliomas. Neurosurgery 62: 505-514; discussion 514-515.

Pascual O, Casper KB, Kubera C, Zhang J, Revilla-Sanchez R, Sul JY et al. (2005). Astrocytic purinergic signaling coordinates synaptic networks. Science 310: 113-116.

Persengiev SP, Devireddy LR, Green MR. (2002). Inhibition of apoptosis by ATFx: a novel role for a member of the ATF/CREB family of mammalian bZIP transcription factors. Genes Dev 16: 1806-1814.

Riquelme PA, Drapeau E, Doetsch F. (2008). Brain micro-ecologies: neural stem cell niches in the adult mammalian brain. Philos Trans $R$ Soc Lond Ser B 363: 123-137.

Santarelli L, Saxe M, Gross C, Surget A, Battaglia F, Dulawa S et al. (2003). Requirement of hippocampal neurogenesis for the behavioral effects of antidepressants. Science 301: 805-809.

Schrot RJ, Ma JH, Greco CM, Arias AD, Angelastro JM. (2007) Organotypic distribution of stem cell markers in formalinfixed brain harboring glioblastoma multiforme. J Neurooncol 85: $149-157$.

Sheng Z, Li L, Zhu LJ, Smith TW, Demers A, Ross AH et al. (2010). A genome-wide RNA interference screen reveals an essential CREB3L2-ATF5-MCL1 survival pathway in malignant glioma with therapeutic implications. Nat Med 16: 671-677.

Shih AH, Dai C, Hu X, Rosenblum MK, Koutcher JA, Holland EC. (2004). Dose-dependent effects of platelet-derived growth factor-B on glial tumorigenesis. Cancer Res 64: 4783-4789.

Singh SK, Clarke ID, Terasaki M, Bonn VE, Hawkins C, Squire J et al. (2003). Identification of a cancer stem cell in human brain tumors. Cancer Res 63: 5821-5828.

Stupp R, Mason WP, van den Bent MJ, Weller M, Fisher B, Taphoorn MJ et al. (2005). Radiotherapy plus concomitant and adjuvant temozolomide for glioblastoma. N Engl J Med 352: 987-996.

Sweger EJ, Casper KB, Scearce-Levie K, Conklin BR, McCarthy KD. (2007). Development of hydrocephalus in mice expressing the G(i)coupled GPCR Rol RASSL receptor in astrocytes. $J$ Neurosci 27: 2309-2317.

Thiel G, Cibelli G. (2002). Regulation of life and death by the zinc finger transcription factor Egr-1. J Cell Physiol 193: 287-292.

Uhrbom L, Hesselager G, Nister M, Westermark B. (1998). Induction of brain tumors in mice using a recombinant platelet-derived growth factor B-chain retrovirus. Cancer Res 58: 5275-5279.

Uhrbom L, Hesselager G, Ostman A, Nister M, Westermark B. (2000). Dependence of autocrine growth factor stimulation in plateletderived growth factor-B-induced mouse brain tumor cells. Int $J$ Cancer 85: 398-406.

Vescovi AL, Galli R, Reynolds BA. (2006). Brain tumour stem cells Nat Rev Cancer 6: 425-436. 
Vinson CR, Hai T, Boyd SM. (1993). Dimerization specificity of the leucine zipper-containing bZIP motif on DNA binding: prediction and rational design. Genes Dev 7: 1047-1058.

Wang H, Lin G, Zhang Z. (2007). ATF5 promotes cell survival through transcriptional activation of Hsp27 in H9c2 cells. Cell Biol Int 31: 1309-1315.

Wang Z, Ahmad A, Li Y, Kong D, Azmi AS, Banerjee S et al. (2010). Emerging roles of PDGF-D signaling pathway in tumor development and progression. Biochim Biophys Acta 1806: 122-130.
Wei Y, Ge Y, Zhou F, Chen H, Cui C, Liu D et al. (2010). Identification and characterization of the promoter of human ATF5 gene. J Biochem 148: 171-178.

\section{This work is licensed under the Creative Commons} Attribution-NonCommercial-No Derivative
Works 3.0 Unported License. To view a copy of this license, visit http://creativecommons.org/licenses/by-nc-nd/3.0/

Supplementary Information accompanies the paper on the Oncogene website (http://www.nature.com/onc) 